\title{
KARL VON HOLTEIS STÜCKE AUF DER BÜHNE DES POSENER STADTTHEATERS
}

\begin{abstract}
Holtei ist ein vielseitig entwickeltes Wesen; er ist Dichter, Redacteur, Schauspieler, Liedersänger, künstlerischer Vorleser, Meister im plaudernden Gespräch und im Briefwechsel gewesen; er war ein wilder fahrender Geselle und ein fleißiger Bücherschreiber; er verlor sich in leichtsinniges, thörichtes Treiben, und gab sich kindlich weich dem stillen Leben der Natur hin und lauschte den ersten Geheimnissen der menschlichen Seele. Eine dunkle Macht jagte ihn in früher Jugend auf die wirren Pfade seines Lebens, und dieser Macht ist er gefolgt, wohin sie ihn führen wollte, ohne ihr bewußten Willen entgegenzustellen. ${ }^{1}$
\end{abstract}

Diese Worte wurden 1878 anläßlich des achtzigsten Geburtstages des Dichters, Schauspielers und Prosaisten Karl von Holtei ausgesprochen, und sie charakterisieren sehr treffend sein ruheloses Leben, so wie es Holtei selbst in der Autobiographie Vierzig Jahre dargestellt hat und wie es auch seine Zeitgenossen gesehen haben. Der heute fast vergessene Künstler wurde an seinem Lebensabend geehrt und gefeiert, obwohl der ästhetische Wert seiner Werke schon damals nicht besonders hoch geschätzt wurde und heute nicht anders als mittelmäßig anzusehen ist. Max Kurnik hat bereits im Todesjahr Holteis nur ein einziges Gebiet seiner dichterischen Tätigkeit bedenkenlos für hervorragend erklärt, nämlich die schlesischen Gedichte. ${ }^{2}$ Tatsächlich werden die schlesischen Gedichte Holteis als seine bedeutendste künstlerische Leistung, als Werk von bleibendem Wert angesehen. Doch es scheint, daß Holtei zeit seines Lebens nicht durch die Poesie, sondern hauptsächlich durch seine Bühnentätigkeit von den Zeitgenossen wahrgenommen wurde, daß nicht die Poesie im Mittelpunkt der ewigen Wanderschaft, die sein Leben ausmachte, stand. Holtei verstand sich sehr lange vor allem als Mann des

\footnotetext{
${ }^{1}$ Max Kurnik: Karl von Holtei. Ein Lebensbild. [Separatdruck aus Nord und Süd] Breslau 1880, S. 10.

${ }^{2}$ Vgl. ebenda, S. 13f. Kurnik sieht in Holtei den „,vorzüglichsten Repräsentanten Schlesiens in der deutschen Poesie" und eine Verkörperung des schlesischen Volkstums schlechthin.
} 
Theaters, und er hat den Großteil seiner Kräfte dem Theater - als Kunstart und als Institution - gewidmet.

Karl von Holtei wurde am 24. Januar 1798 in Breslau in einer alten Adelsfamilie geboren. ${ }^{3}$ Seine Mutter starb bei der Geburt, und der Vater - ein Husarenoffizier - schickte ihn zum Freiherrn von Arnold. Hier, im Haus des reichen Verwandten, verbrachte Holtei, von der Tante erzogen, seine Kindheit - entweder im Breslauer Haus der Familie oder (im Winter) auf einem Gut unweit der Stadt. Nach dem Tod seines Pflegevaters wurde der junge Holtei für vier Jahre in einer Erziehungsanstalt untergebracht. Dann besuchte er das Magdaläums-Gymnasium in Breslau. Nachdem die finanzielle Not seine Mutter gezwungen hatte, den Jungen aus der teuren Pension zurück nach Hause zu holen, entdeckte er das Theater für sich. Die Bühne faszinierte ihn so sehr, daß der dreizehnjährige Karl von Holtei den Entschluß faßte, Schauspieler zu werden. Die Tante war nicht sehr angetan von seinen Plänen und versuchte, sie ihm auszureden. Holtei verkehrte nun in den Kreisen der Breslauer Schauspieler und Schauspielerinnen und wurde von seiner Leidenschaft zum Theater so hingerissen, daß er sogar einmal einen Monat lang dem Schulunterricht fernblieb. Das war für die Familie zu viel; sie beschloß, ihn aufs Land, ins Dorf Obernigk (heute Oborniki Śląskie) zur landwirtschaftlichen Ausbildung zu schicken. Es fügte sich damals so, daß Holtei wegen eines Pamphlets vom Gymnasium gewiesen werden sollte; er kam dieser Strafe durch seine Reise nach Obernigk also zuvor. Hier las er viel und schrieb an seinen ersten Operntexten und Schauspielen. Nach der Flucht Napoleons von der Insel Elba trat der junge Holtei freiwillig in das Schlesische Reserve-Armee-Corps („Breslauer freiwillige Jäger") ein. Sogar beim Militär ging er seiner Liebe zum Theater nach; er wurde von dem damals berühmten Rezitator Baron von Sydow in die Vortragskunst, die ihm später so viel Lob einbrachte, eingeweiht. In seiner Freizeit verfaßte der angehende Dichter Liedertexte, die dann von seinen Kameraden gesungen wurden. Nach dem Militärdienst kehrte Holtei nach Breslau zurück, um hier Jura, Geschichte, Literaturgeschichte und Philosophie zu studieren. Inzwischen verbrachte er einige Zeit am Privattheater des Grafen von Herberstein, wo er auch seine zukünftige Frau, die Schauspielerin Luise Rogee, kennenlernte. In Breslau entstanden die ersten Stücke Karl von Holteis; 1819 debütierte er als Autor mit dem Spiel Die Farben auf der Breslauer Stadtbühne. Im selben Jahr stand Holtei zum ersten Mal als Schauspieler auf der Bühne dieses Theaters, allerdings mit wenig Erfolg. 1821 heiratete er Luise Rogee und wurde am Breslauer Stadttheater, in dem sie als Schauspielerin angestellt war, als Sekretär und Theaterdichter engagiert. Hier gründete Holtei die Schrift „Deutsche Blätter für Poesie, Literatur, Kunst und Theater" und wurde gleichzeitig Herausgeber des „Obernigker Boten“. Mit Luise hatte er zwei Kinder - einen Sohn und eine Tochter. Die Atmosphäre war aber damals in Breslau für die Holteis nicht besonders gut. Man hat den jungen Adligen als Schauspieler eher mit Zurückhaltung angenommen, er selbst konnte kaum

${ }^{3}$ Die folgenden Angaben zum Leben Holteis entstammen hauptsächlich der Autobiographie des Dichters. Vgl. Karl von Holt ei: Vierzig Jahre. Breslau 1862. 
andere Menschen für sich gewinnen. Die Folge davon war schließlich, daß die Holteis 1823 Breslau verlassen mußten.

So begann die „Wanderschaft" Holteis, die das Wesen seines Lebens bis in die vierziger Jahre hinein prägen sollte. Das Paar wandte sich zuerst nach Prag und Wien, um dann nach mehreren gemeinsamen Auftritten in Berlin anzukommen, wo Luise am Königlichen Theater angestellt wurde. Beide gewannen hier viele Freunde, darunter auch Polen. Holtei selbst wurde in kurzer Zeit als Dramenvorleser ${ }^{4}$ bekannt. Nach dem frühen Tod Luisens (1825) übernahm Holtei für kurze Zeit den Posten des Direktionssekretärs und Bühnendichters am Königlichen Theater. Hier entstanden seine erfolgreichen Stücke Wiener in Berlin und Wiener in Paris; am 1. Dezember 1825 wurde Holteis Drama über Tadeusz Kościuszko, Der alte Feldherr, uraufgeführt, ein Drama, das Holtei seinen polnischen Freunden in Breslau gewidmet hatte. ${ }^{5}$ Wahrscheinlich war es der Breslauer Freundeskreis, der den Dichter mit dem ,alten Feldherrn“"vertraut gemacht hatte. Die in dieser Zeit unter den Polen stets wache Erinnerung an die polnischen Freiheitskämpfe erweckte bei dem bewährten Polenfreund (für einen solchen galt Holtei zu Recht) ein reges Interesse an Kościuszko. Seit seiner Jugend und auch in der Studienzeit nahm der Dichter regen Anteil an den Belangen Polens und der Polen. Für seine polnischen Freunde setzte er sich ein, sei es persönlich, sei es mit seinen „Polengedichten“, die Holtei als einer der ersten - noch vor der großen Welle der Polenbegeisterung in Deutschland - schrieb. Für seinen Autor war das Liederspiel über Kościuszko nicht bloß wegen der großen Popularität, die es ihm einbrachte, wichtig. Die Persönlichkeit des Titelhelden war ihm besonders nahe, er wollte in Kościuszkos ruhelosem Leben - wie in einem Spiegel - Reflexe der eigenen Existenz sehen. Mit zeitlichem Abstand, fast zwei Jahrzehnte nach der Entstehung des Stückes, schrieb Holtei in seinen Erinnerungen: „Wenn der alte Sänger ein wandernder geworden, wenn er wie er hier vor Ihnen erschien, ein heimatloser ist, so darf er fast behaupten, Kościuszkos Geist habe ihn zum Zigeuner gemacht. "6

Doch in Berlin war Der alte Feldherr seitens der Behörden Ende der zwanziger Jahre nicht gern gesehen. Nach sechs Aufführungen wurde das Stück verboten, obwohl der König selbst eine besucht hatte. Das Zensurverbot in Berlin verhinderte jedoch nicht, daß das Stück binnen kurzer Zeit in Hamburg, Breslau, Danzig und Posen erfolgreich auf die Bühne kam. ${ }^{7}$ Das Drama über den ,,alten

${ }^{4}$ Er las sehr gern Dramen von Shakespeare vor. Später wurden einige der Dramen Shakespeares von Holtei bearbeitet und auf deutschsprachigen Bühnen aufgeführt, z.B. Viel Lärm um Nichts (1849) und die Komödie der Irrungen (1852). Diese beiden Stücke wurden im Februar 1854 im Posener Stadttheater aufgeführt.

${ }^{5}$ Folgende Widmung ist in der Textausgabe aus dem Jahr 1828 zu finden: „Zur Erinnerung froh durchlebter Jugendzeit widme ich meinen lieben Freunden in Polen den Alten Feldherrn." Zit. nach Edyta Połczyńska: Karl von Holteis Kościuszko-Verehrung. In: Studia Germanica Posnaniensia XIV/1990, S. 8. Die Rolle des polnischen Nationalhelden Kościuszko im Leben des Dichters sowie die Bedeutung des Dramas im Holteischen Schaffen hat Edyta Połczyńska im vorstehend genannten Artikel ausführlich dargestellt.

${ }^{6}$ Zit. nach Połczyńska (wie Anm. 5), S. 3.

${ }^{7}$ Vgl. ebenda, S. 8f. Wie den Theaterzetteln zu entnehmen ist, kam Der alte Feldherr in Poznań „auf vieles Verlangen“ am 12. November 1826 erstmals zur Aufführung. 
Feldherrn" existierte folglich schon, als nach dem Novemberaufstand die polnischen Flüchtlinge durch Deutschland zogen. Des öfteren wurden sie hier mit einer Aufführung des Werkes begrüßt. Die Liedeinlagen aus dem historischen Liederspiel über Kościuszko (die bekannteste: „Denkst du daran, mein tapfrer Lagienka“) haben sich bald verselbständigt ${ }^{8}$ - unter den Polen wie unter den Deutschen. Holtei hörte einige von ihnen sogar bereits ein Jahr nach der Erstaufführung des Dramas auf Pariser Straßen und war verständlicherweise sehr erfreut darüber. Bald waren sie nahezu überall zu hören, selbst im Hause Goethes, wenn der Breslauer Dichter dort begrüßt werden sollte.

Nach einem kurzen Aufenthalt im schlesischen Grafenort, wo die Mehrheit der schlesischen Gedichte entstand, reiste Holtei bereits 1826 nach Paris, wo er zahlreichen Persönlichkeiten der Epoche begegnete (u.a. Gioacchino Rossini, Wilhelm von Humboldt, Marie Joseph Lafayette). Die Rückreise über Weimar brachte die Bekanntschaft mit Goethe und die Freundschaft mit dessen Sohn August sowie auch mit Johanna Schopenhauer. Einige Zeit später lernte Holtei bei Goethe auch Adam Mickiewicz kennen. Über die enge Beziehung mit Johanna Schopenhauer legen ihre Briefe an Holtei ein beredtes Zeugnis ab. ${ }^{9}$ Goethe brachte dem Holteischen Schaffen des öfteren Ironie und Unduldsamkeit, jedoch auch Anerkennung entgegen; Holtei selbst zitiert in seinen Erinnerungen Vierzig Jahre die Goetheschen Worte: „Dieser Mensch ist eine Art Improvisator auf dem Papiere; es scheint ihm sehr leicht zu werden, aber er sollte sich's nicht so leicht machen. " ${ }^{10}$ Goethe hat wohl in dem jungen Dichter - nach der Lektüre einiger seiner Werke und nach mehreren Besuchen Holteis im Hause des Geheimrats - diese drei Eigenschaften erkannt, die sich dann in dessen ganzem Leben und Schaffen ausprägen sollten: Sentimentalität, Disziplinlosigkeit und Lebenslässigkeit. ${ }^{11}$

Um das Jahr 1827 entstand das Stück Lenore, das mit großem Erfolg in Berlin aufgeführt wurde. Die Titelrolle spielte Julie Holzbecher, die drei Jahre später Holteis Frau wurde. 1828 erschienen Holteis Schlesische Gedichte. Mißverständnisse mit der Direktion des Berliner Theaters zwangen das Paar jedoch, nach Darmstadt zu ziehen, wo Julie einige Zeit lang am Hoftheater spielte. Darauf folgte eine Gastspielreise nach Wien und in andere Städte.

Anfang der dreißiger Jahre entstanden die nächsten Stücke: Hans Jürge, Lorbeerbaum und Bettelstab, Der dumme Peter, Wiener in Paris, Shakespeare in der Heimat sowie der von Hans Gläser vertonte Operntext Des Adlers Horst. Während Julie einen festen Vertrag mit dem Berliner Theater bekam, konnte Holtei - u.a. wegen seines Rufs als Revolutionär - keine dauerhafte Anstellung finden. Auch als Schauspieler war er hier nicht erfolgreich. Verbittert reiste er erneut durch mehrere Städte, um dann, nach seiner Rückkehr in Berlin, wieder als Dramenvorleser zu glänzen. Schließlich verbrachte Holtei mit seiner Frau einige Monate in und bei Breslau, wo er seine kommenden Gastspielreisen vorbereitete. Die nächste

\footnotetext{
${ }^{8}$ Ebenda, S. $13 \mathrm{ff}$.

${ }^{9}$ Vgl. Johanna Schopenhauer: Briefe an Karl von Holtei. Leipzig 1970.

${ }^{10}$ Zit. nach Wolfgang B a umgart: Carl von Holtei. Würzburg 1958, S. 6.

${ }^{11} \mathrm{Vgl}$. ebenda.
} 
Reise führte das Ehepaar Holtei erneut nach Wien. Hier ernteten die Eheleute überall Beifall und erlebten einen der größten Erfolge ihres Lebens. Die Einnahmen aus den Aufführungen der Holteischen Stücke und jener, in denen das Paar auftrat, konnten das Wiener Josephstädter Theater vor dem Bankrott retten. Mittlerweile wurden Holteis Stücke auf verschiedenen Bühnen gespielt. Kurz vor der Posener Erstaufführung des Dramas Lorbeerbaum und Bettelstab (1834) berichtete die „Zeitung des Großherzogthums Posen“ über das Wiener Ereignis:

[...] das Holteische Drama „Lorbeerbaum und Bettelstab“ [ist] in Wien kürzlich 7 Mal in 7 Tagen zur Aufführung gekommen, und das Holteische Ehepaar [wurde] bei der ersten Aufführung zehn Mal herausgerufen [...]. Begreife, wer's kann! ${ }^{12}$

Doch auch Wien verließ Karl von Holtei verbittert und enttäuscht. Intrigen anderer und seine Unfähigkeit, sich die Gunst des Publikums und der Honoratioren zu sichern, veranlaßten Holtei und seine Frau zur Rückkehr in die Heimat, nach Grafenort, wo er bald den Tod seines Sohnes erleben mußte. Die erneuten Versuche, in Berlin eine Anstellung zu bekommen, schlugen fehl. Den Entschluß, endgültig mit dem Theaterleben zu brechen, vereitelte jedoch ein Angebot aus Riga, dort den Posten als Direktor des Stadttheaters zu übernehmen. Der Dichter willigte gern ein.

Die beiden überaus glücklichen Jahre in Riga, wo Holtei viele Freunde fand, endeten allerdings mit dem Tod seiner zweiten Frau und der Zwillinge, die sie ihm gebar. Dieser Schicksalsschlag trieb den ewigen Wanderer erneut in die Welt. Er verbrachte einige Zeit in Graz und in Wien, dann mietete er wieder eine Wohnung bei Berlin. Die Jahre 1840 bis 1850 führten ihn noch einmal auf eine Reise als Vorleser durch Deutschland, aber er hielt sich nirgendwo länger auf. Nacheinander wurden Holteis Erinnerungsbände Vierzig Jahre fertig. Damals entstand u.a. auch das Zeitstück Zum grünen Baum, das Holtei als eines seiner besten Werke erachtete.

Damit endete eine Etappe im Holteischen Leben. Wolfgang Baumgarten nannte die Leidenschaft, die diesen Mann fast ein halbes Jahrhundert durch die Welt trieb, „eine Liebhaberei, die zum Beruf wurde "13 - womit er zugleich das dramatische Schaffen Holteis charakterisierte, das sich eher am Tagesbedarf orientierte und keinen Anspruch auf bleibenden künstlerischen Wert erhob. Max Kurnik würdigte die beiden flüchtigsten Schaffensbereiche Holteis - seine Virtuosität als Vorleser und Plauderer:

In beiden Beziehungen war er ein seltener Meister, und beides hat ihm auf den vielverschlungenen Lebenspfaden gar oft die Wege ebnen geholfen. Der Vorleser Holtei war weit und breit in Deutschland berühmt. [...] Als dramatischer Vorleser [...] war er entschieden vollendeter Künstler. ${ }^{14}$

Das Jahr 1850 bedeutete eine entscheidende Wende im Leben des bisher so unruhigen Dichters: Er ließ sich in Graz nieder und begann Romane zu schreiben.

\footnotetext{
${ }^{12}$ Zeitung des Großherzogthums Posen, 1834, Nr. 286.

${ }_{13}^{13}$ B aumgart (wie Anm. 10), S. 8.

${ }^{14}$ Kurnik (wie Anm. 1), S. 19.
} 
Die Ereignisse in Polen führten in seiner bisher positiven Einstellung zu den Polen eine Änderung herbei: Sein Engagement für dieses Land stellte er ein. Nach 1850 entstanden Romane, unter denen vor allem Christian Lammfell, Die Vagabunden, Der letzte Komödiant und der Kriminalroman Mord in Riga zu nennen sind. Holtei selbst charakterisierte sein episches Werk als schwatzhaft, mit Recht. In einem Jahrzehnt entstanden etwa 20 bis 30 Bände. ${ }^{15}$ Die meisten seiner Prosawerke haben bis heute lediglich noch einen informativen und historischen Wert bewahrt. Letzteres gilt aber vor allem für seine Memoiren. In den Jahren 1864 bis 1880 lebte Holtei wieder in seiner Heimatstadt Breslau, wo er am 12. Februar 1880 im Alter von 82 Jahren gestorben ist.

Bisher fanden sich keine Nachweise dafür, daß Karl von Holtei auch in Posen gewesen ist. Die uns noch heute zugänglichen Quellen bestätigen aber, daß viele seiner Stücke im Posener Stadttheater aufgeführt wurden. Nicht alle Theaterzettel der Posener Bühne sind erhalten geblieben, das gilt auch für die Zeitungen aus dieser Zeit. Der Zahn der Zeit ließ nur einige Jahrgänge dieser Dokumente unversehrt, allerdings auch das nicht in vollem Umfang. Was dennoch möglich erscheint, ist stichprobenweise vorzugehen, um daraus die wahrscheinlichsten Schlüsse zu ziehen.

Eines kann als sicher gelten: Die Theaterzettel des Posener Stadtheaters legen eindeutig Zeugnis darüber ab, daß die Dramen, Komödien, Vaudevilles und Opern des wandernden Dichters einen festen Bestandteil im Spielplan der Bühne von den zwanziger Jahren bis in die letzten Jahrzehnte des 19. Jahrhunderts hinein bildeten. Karl von Holtei gehörte mit 69 Aufführungen seiner Stücke in der Zeit von 1826 bis $1847 \mathrm{zu}$ den fünf meistgespielten Autoren (neben Kotzebue, Angely, Raupach und Charlotte Birch-Pfeiffer) und dürfte sich daher auch beim Posener Publikum großer Beliebtheit erfreut haben. In derselben Zeit erlebten die Dramen von Schiller nur 59 Aufführungen. ${ }^{16}$ Auch wenn die Holteischen Werke selten mehr als zweimal hintereinander oder in kurzen Abständen gespielt wurden, kann festgestellt werden, daß sie meistens - abgesehen von Einzelfällen - beim Publikum gut ankamen. Auf vielen Theaterzetteln ist neben dem Titel und Datum ein kurzer Vermerk zu lesen, daß das jeweilige Stück ,auf vieles Verlangen“"bzw. ,auf allgemeines Verlangen“ aufgeführt wird. Bereits ein Jahr nach seiner Uraufführung hatte auch das Posener Publikum Gelegenheit, Den alten Feldherrn zu sehen; das war am 12. 11. 1826. Dieses in Berlin kurz nach der Premiere verbotene Stück wurde in den folgenden Jahren (eine Aufführung ist im Jahr 1840 nachweisbar, doch aller Wahrscheinlichkeit nach wurde dieses Stück gelegentlich auch noch später gespielt) noch oft in der von Polen und Deutschen bewohnten Stadt gezeigt. Es wäre also offensichtlich falsch, anzunehmen, daß hier ein so ,polnisches“ Drama von den Behörden für besonders gefährlich erachtet wurde. Die Direktion des Theaters förderte den

15 Zofia Kubrakiewicz: Karl von Holtei auf dem Hintergrunde des deutschen Theaters seiner Epoche - und sein Verhältnis zu Polen auf Grund seiner dramatischen Werke. Wrocław 1950, Diss., S. 51 .

${ }^{16}$ Edyta Połczyńska: Im polnischen Wind. Beiträge zum deutschen Zeitungswesen, Theaterleben und zur deutschen Literatur im Großherzogthum Posen 1815 - 1918. Poznań 1988, S. 30. 
Besuch des polnischen Publikums sogar besonders, indem sie die Theaterzettel auch in polnischer Sprache herausgab. Erst in den späten vierziger Jahren verschwand „Holteis, wegen seiner ansprechenden Melodien gern gesehener , alter Feldherr “ “17 von den Plakaten.

Einige der Holteischen Bühnenwerke wurden in Posen früher als in Breslau aufgeführt, z.B. sein von den Regierenden so gut und gerne aufgenommenes „,vaterländisches Schauspiel mit Gesang in drei Abteilungen“"Lenore. Die Posener Erstaufführung des Stücks fand am 27.11. 1828 (in Breslau erst 1829) statt, fünf Monate nach seiner erfolgreichen Uraufführung in Berlin. Lenore kam beim Posener Publikum so gut an, daß es sich noch viele Jahre im Spielplan halten konnte. Gespielt wurde die Lenore in Posen bis in die siebziger Jahre hinein, vielleicht sogar noch länger. Ein paar Tage nach der ersten Vorstellung versuchte die „Zeitung des Großherzogthums Posen“, die Direktion des Stadttheaters mit einer „eingesandten“ anonymen Korrespondenz zur erneuten Aufführung der Lenore zu bewegen:

Mehrere Theaterfreunde, die schon längst den Wunsch gehegt haben, Holteis berühmtes, ächt nationelles Melodram, Lenore, zu sehen, die aber behindert waren, der unlängst stattgehabten Darstellung desselben beizuwohnen, ersuchen hiermit Herrn Vogt, ${ }^{18}$ doch am nächsten Sonntage dieses Melodram zu repetieren. Da die erste (dem Vernehmen nach höchst gelungene) Vorstellung sich eines so rauschenden Beifalls zu erfreuen gehabt hat, so glauben wir, daß eine Wiederholung am Sonntage im Interesse des Herrn Vogt liegt, denn unstreitig ist die Zahl derer, die an den Wochentagen behindert sind, das Theater zu besuchen, die aber doch gern dieses, überall mit glänzendem Beifall aufgenommene Melodram sehen möchten, sehr groß. Wir sind daher überzeugt, daß Herr Vogt sich eines recht zahlreichen Besuches zu erfreuen haben wird. ${ }^{19}$

Und es wurde ein Erfolg. Schon bald konnte der anonyme Autor der Zeitung seiner Freude über die gelungene Vorstellung Ausdruck verleihen:

Die Aufführung der „Lenore“ am Sonntage hatte ein zahlreiches Publikum versammelt, das insgesamt durch die recht gelungene Darstellung zufriedengestellt wurde; besonders brav war Herr Gustav Räder. Ref. freut sich, daß Herr Vogt wieder den richtigen Weg einschlägt, um das Publikum aufs neue zu gewinnen. ${ }^{20}$

Im Winter 1833 wurde eine Vorstellung der Lenore für wohltätige Zwecke gegeben. Aus den Einnahmen für die Billets ersten Ranges wurde ein Holzankauf für die Armen der Stadt Posen finanziert. Dasselbe Stück konnten die Posener auch am 9.6.1836 ,zur Feier der Anwesenheit Seiner Königlichen Hoheit des Kronprinzen Friedrich Wilhelm von Preußen“ sowie am 3. 8. 1839 ,zur Feier des

${ }^{17}$ Zeitung des Großherzogthums Posen, 1834, Nr. 140.

${ }^{18}$ Dem Schauspieldirektor Ernst Vogt, der die Posener Bühne von 1828 bis 1852 leitete, verdankte dieses Theater seine Entwicklung und Stabilisierung. Vogt sorgte als erster Theaterleiter in größerem Umfang auch für den Besuch des polnischen Publikums. In seiner Amtszeit besuchten polnische Theatergesellschaften Posen, er selbst besuchte mit den Schauspielern des Posener Stadttheaters andere Städte der Provinz, vor allem Bromberg [Bydgoszcz]. Vgl. Połczyńska (wie Anm. 16), S. $29 \mathrm{ff}$.

${ }^{19}$ Zeitung des Großherzogthums Posen, 1831, Nr. 129.
${ }^{20}$ Zeitung des Großherzogthums Posen, 1831, Nr. 134. 
allerhöchsten Geburtstagsfestes Seiner Majestät des Königs" sehen. Lenore war ebenso das Holteische Stück, das 1845/46 auf der Bromberger Gastspielreise des Posener Stadttheaters gespielt wurde, wahrscheinlich áuch eines der wenigen, wenn nicht das einzige von Holteis ,ernsteren“ Stücken, das sich sehr lange - bis in die letzten Jahrzehnte des 19. Jahrhunderts - der Gunst des Publikums erfreuen konnte und gleichermaßen bei offiziellen staatlichen Feiern aufgeführt werden durfte. In Berlin wurde Lenore 1866 als „nationales Feststück“ - aus Anlaß des Einzugs der königlichen Truppen - neben Lessings Minna von Barnhelm gegeben.

Das Posener Publikum sah sich freilich genauso gern die leichteren Bühnenwerke des Dichters an: Die Wiener in Berlin (eines der populärsten Stücke Holteis überhaupt), Berliner in Wien, Allen ist geholfen und Dreiunddreißig Minuten in Grüneberg. Alle diese Stücke erlebten in Posen mehrere Aufführungen. Seine Beliebtheit begann mit Die Wiener in Berlin, in den vierziger Jahren setzte dann die Liederposse Dreiunddreißig Minuten in Grüneberg, oder: Der halbe Weg seinen Erfolg fort. Seltener sah man das Lebensbild Pariser in Wien oder das Vaudeville Ein Achtel vom großen Loos. Die leichteren Produktionen kamen dem Geschmack des Publikums, dem täglich vor allem Stücke von Kotzebue oder Angely angeboten wurden, wohl näher als die anderen. Nicht immer war man von Holteis Stücken ausnahmslos begeistert. Der angesichts der Lenore-Aufführungen gezeigte Enthusiasmus verschwand zuweilen bei anderen Darbietungen. Mit diesem wechselnden Erfolg - als Dramatiker wie auch als Schauspieler - mußte Holtei leben; das Publikum feierte ihn begeistert und lehnte ihn zuweilen ebenso heftig ab.

Des Adlers Horst, die am 22. 7. 1834 erstmals in Posen aufgeführte ,große romantisch-komische Oper in drei Akten", im allgemeinen positiv rezipiert, wurde vom Redakteur der „Zeitung des Großherzogthums Posen“ sehr zwiespältig wahrgenommen. Er wußte offenkundig nicht so recht, wie das Bühnenwerk dieses berühmten Holtei einzuschätzen sei.

\footnotetext{
Über die Oper „Des Adlers Horst“ zu berichten fühlt sich der Referent außer Stande, da es nach einmaligem Anhören derselben den Geist dieses neuen Tonwerkes noch nicht hat erfassen können. Kenner loben die durchweg korrekte, teilweise auch geniale Composition und bezeichnen besonders die komischen Partien als höchst gelungen. Der erste Akt möchte wohl der schwächste sein; der zweite hat das herrliche Trink-Terzett und ein sehr schönes Finale aufzuweisen; im dritten nimmt die Musik einen schweren großartigen Charakter an. Der Eindruck, den diese Oper auf die hiesigen Zuschauer machte, war verschieden; die wirklichen Kenner waren befriedigt. Ein Urtheil über die Darstellung behält sich Ref. noch vor. ${ }^{21}$
}

Allerdings gab es mitunter viel schärfere Urteile über die Aufführungen Holteischer Stücke. Es ist interessant, die Geschichte der Posener Erstaufführung des wohl persönlichsten Bühnenwerks des Autors - Lorbeerbaum und Bettelstab - in der „Zeitung des Großherzogthums Posen“ zu verfolgen. Die Nachricht, daß dieses überall einen so guten Ruf genießende Stück zum Benefiz eines der besten Schauspieler hiesiger Bühne gewählt wurde, erfreute die Zeitung dermaßen, daß man schon vorher eine fast enthusiastische Meldung

\footnotetext{
${ }^{21}$ Zeitung des Großherzogthums Posen, 1834, Nr. 171.
} 
darüber brachte. Sowohl der Geschmack des Benefizianten bei der Wahl des Dramas als auch sein Verfasser wurden gelobt, ohne daß dieses Stück vorher gesehen wurde. Die Vorfreude steigerte man noch dazu durch Meldungen aus Wien. ${ }^{22}$ Der Benefizabend am 4. 12. 1834 sollte eines der größten Ereignisse am Stadttheater werden, das nur noch durch die persönliche Teilnahme des Dichters übertroffen werden könnte.

$\mathrm{Zu}$ den Dichtungen, die im Gebiete der Bühnenliteratur in der jüngsten Zeit Glück gemacht haben, gehört auch Holteis „Lorbeerbaum und Bettelstab, oder: 3 Winter eines deutschen Dichters“, Schauspiel mit Gesang, Musik von Rieß; nebst einem Nachspiele: „Bettelstab und Lorbeerkranz, oder: 20 Jahre nach dem Tode". Der Verfasser als Bühnendichter und genialer Vorleser sattsam bekannt, wählte - nachdem er selbst zur Bühne übergetreten - dies Drama zu seinen eigenen Kunstleistungen und erntete damit überall entschiedenen Beifall. Vergebens haben wir gehofft, daß der Dichter von Breslau aus auch zu uns kommen und seine gemüthlichen Dichtungen bei uns selbst einführen würde; um so mehr muß es uns freuen, daß eines der fleißigsten und beliebtesten Mitglieder unserer Bühne, Herr Heinisch, das gesamte Drama zu seiner nächstens zu gebenden Benefizvorstellung gewählt hat. Es gereicht dem Herrn Heinisch zur Ehre und beweist seinen Kunstsinn [...], und wir wollen hoffen, daß das Publikum durch einen recht zahlreichen Besuch seine Bestrebungen lohnen werde. Stück und Benefiziant verdienen es wohl! $!^{23}$

Doch die Vorstellung fiel durch. Der Berichterstatter der ,Zeitung des Großherzogthums Posen" war nach der Premiere nicht mehr so begeistert wie vorher. Er vermißte den dramentypischen Aufbau und kritisierte die Schauspieler für ihre unzulängliche Vorbereitung der ohnehin schon schwach geschriebenen Rollen. Für ihn war alles zu trüb und zu matt.

Holteis „Lorbeerbaum und Bettelstab“ beweist abermals, daß man sich auf den Ruf eines Stücks nicht unbedingt verlassen dürfe, denn es ist dies nicht Gedicht, nichts weniger, als ein wohl gegliedertes Drama, sondern eine Reihe von einzelnen, locker verbundenen Lebensscenen, ja gewißermaßen nur eine einzige Rolle, der alle übrigen zur dürftigen Folie dienen. [...] Was die Aufführung anbetrifft, so kann wohl nur von der Darstellung des armen Dichters die Rede sein, da alle übrigen Rollen vom Dichter dergestalt vernachlässigt sind, daß man es den Schauspielern kaum zumuthen kann, auf dieselben einigen Fleiß zu verwenden. Das hatten sie denn auch hier nicht gethan, weshalb das Publikum die Auffassung des Zusammenhangs lediglich den lauten Bestrebungen des Souffleurs verdankte. ${ }^{24}$

Nur das Spiel des Hauptdarstellers wurde positiv beurteilt, sei es, weil dies wirklich so war oder um den Benefizianten zu retten. Das Nachstück Bettelstab und Lorbeerbaum, oder: Zwanzig Jahre nach dem Tode gefiel dem Rezensenten „ungleich besser" und wurde für seine Geschlossenheit gelobt. Unverständlich schien das Finale des Stückes, wo ein „durch den Gang der Begebenheit bedingter tragischer Ausgang durch einen gewöhnlichen matten Schluß ersetzt" wurde. Folglich war dieses „Erzeugnis eines bis ins innerste verstimmten Gemütes“25 auf den Brettern der Posener Stadtbühne lange nicht mehr zu sehen.

\footnotetext{
${ }^{22} \mathrm{Vgl}$. die S. 29.

${ }_{23}^{23}$ Zeitung des Großherzogthums Posen, 1834, Nr. 278.

${ }^{24}$ Zeitung des Großherzogthums Posen, 1834, Nr. 287.

${ }^{25}$ Ebenda.
} 
Noch schlechter wurde sechs Jahre später Der dumme Peter bewertet. Man warf diesem Stück vor, es sei „ein schwaches Produkt ohne innere Notwendigkeit und Charakterwahrheit", ${ }^{26}$ dazu kamen noch Schwächen der Aufführung - die Schauspieler „kannten den Text in einem unbefriedigenden Maße“. Der Rezensent räumte jedoch ein, daß nicht alles, was er beanstandete, in gleicher Weise auch von den Zuschauern abgelehnt wurde. Kann das aber im Falle eines auf den Geschmack des Publikums hin geschriebenen Stückes verwundern? Dieselben Vorwürfe tauchten bei anderen Werken Karl von Holteis nur allzuoft auf. Seine Stücke wurden für den Mangel an ,dramatischem Gehalt" oder für das Ausbleiben ,einer eigentlichen Katastrophe ${ }^{\text {“27 }}$ kritisiert, man beanstandete, daß sie im Grunde genommen keine geschlossenen Dramen seien. Gleichzeitig hörte man jedoch zu den verschiedensten Anlässen gern Lieder aus Holteis Stücken, die in die Literatur und in das allgemeine Kulturleben aufgenommen wurden. Die Popularität der Holteischen Werke stand sehr lange im Widerspruch zu ihrer Beurteilung - bis sie im 20. Jahrhundert völlig vergessen wurden. Das Spezifische der Stücke Holteis, die sich sehr lange auf den deutschsprachigen Bühnen behaupten konnten, versuchte ein unvoreingenommener Kritiker noch zu Lebzeiten des Dramatikers zu ergründen und zugleich zu würdigen:

Ohne die vielfach von der Kritik gerügten Schwächen der dramatischen Muse Holteis zu verkennen, muß doch [...] zugegeben werden, daß ein schon 60 Jahre andauernder Erfolg [Holteis] auf der Bühne eine Thatsache ist, die ein gewichtiges Urtheil in sich schließt, eine Thatsache, die man fast als ein Ereignis bezeichnen möchte, da, wenn man von den Klassikern absieht, die Zahl der dramatischen Autoren, denen eine gleiche Lebensdauer auf der Bühne beschieden war, äußerst gering ist. Und der Grund dieses seltenen Erfolges liegt in der eigenthümlichen Mischung von Humor und Sentimentalität, die sich, wie in der Persönlichkeit des Dichters, so auch in seinen dramatischen Werken offenbart. ${ }^{28}$

\begin{abstract}
ANHANG
Die heute nachweisbaren Aufführungen der Holteischen Werke auf der Bühne des Posener Stadttheaters in den Jahren 1826 bis $1871^{29}$
\end{abstract}

30. 06. Die Wiener in Berlin. Liederposse in einem Aufzuge.

06. 08. Die Wiener in Berlin. Liederposse in einem Aufzuge.

12. 11. Der alte Feldherr. Historisches Liederspiel in einem Akt [Posener Erstaufführung].

16. 12. Der alte Feldherr.

Die Berliner in Wien.

${ }^{26}$ Zeitung des Großherzogthums Posen, 1840, Nr. 254.

${ }^{27}$ So der Redakteur der Posener Zeitung über den Holteischen Shakespeare in der Heimath. In: Zeitung des Großherzogthums Posen, 1840, Nr. 226.

${ }^{28}$ Kurnik (wie Anm. 1), S. 17.

29 Die Zusammenstellung entstand anhand der Theaterplakate, die im Posener Staatsarchiv aufbewahrt werden: Archiwum Państwowe w Poznaniu, Akta Miasta Poznania, Sign. 3661-3690, sowie nach Berichten aus der „Zeitung des Großherzogthums Posen“. 
07. 12. Der Kalkbrenner. Possen mit Gesang in einem Akt.

Allen ist geholfen. Lustspiel in einem Akt [Posener Erstaufführung].

17. 12. Allen ist geholfen.

1828

15. 06. Die Wiener in Berlin.

28. 06. Kościuszko. Der alte Feldherr. Liederspiel in einem Akt.

27. 11. Lenore. Vaterländisches Schauspiel mit Gesang in drei Abteilungen. Musik von Eberwein [Posener Erstaufführung].

1829

12. 06. Die Wiener in Berlin.

05. 07. Kościuszko. Der alte Feldherr.

08. 07. Die Wiener in Berlin.

10. $07 . \quad$ Kościuszko. Der alte Feldherr.

04. 10. Die Wiener in Berlin.

09. 10. Die Wiener in Berlin.

1830

17. 01. Der Kalkbrenner. Vaudeville in einem Akt.

1831

02. $06 . \quad$ Lenore.

12. $06 . \quad$ Lenore.

05. 11. Die Wiener in Berlin.

25. 12. Die Wiener in Berlin.

1833

05. 02. Kościuszko. Der alte Feldherr.

09. 03. Der alte Feldherr.

09. 04. Robert, der Teufel. Großes romantisches Schauspiel mit Musik in fünf Akten.

22. 08. Der alte Feldherr.

22. 09. Der alte Feldherr.

31. 10. Die Wiener in Berlin.

03. $12 . \quad$ Lenore.

08. $12 . \quad$ Lenore.

1834

06. 02. Der alte Feldherr.

17. 06. Der alte Feldherr. [Neu bearbeitet].

19. 06. Der alte Feldherr.

22. 07. Des Adlers Horst. Große romantisch-komische Oper in drei Akten. Musik von Kapellmeister Herrn Franz Gläser [Posener Erstaufführung].

23. 07. Des Adlers Horst. Große romantisch-komische Oper in drei Akten.

06. 11. Des Adlers Horst. Große romantisch-komische Oper in drei Akten. 
04. 12. Lorbeerbaum und Bettelstab, oder: Drei Winter eines deutschen Dichters. Schauspiel in drei Akten mit einem Nachspiel: Bettelstab und Lorbeerbaum, oder: Zwanzig Jahre nach dem Tode [Posener Erstaufführung].

1835

10. 05. Die Wiener in Berlin.

03. 07. Der alte Feldherr.

07. 07. Des Adlers Horst. Große romantisch-komische Oper in drei Akten.

1836

09. $06 . \quad$ Lenore.

1839

03. 02. Die Kindesräuber in Berlin. Schauspiel in drei Aufzügen [Posener Erstaufführung]. Der alte Feldherr.

09. 06. Der alte Feldherr.

03. 08. Lenore.

22. 09. Ein Achtel vom großen Loose. Liederposse in einem Akt [Posener Erstaufführung].

24. 09. Dreiunddreißig Minuten in Grüneberg oder Der halbe Weg. Liederposse in einem Akt [Posener Erstaufführung].

27. 09. Dreiunddreißig Minuten in Grüneberg.

29. 09. Die Wiener in Berlin.

15. 12. Dreiunddreißig Minuten in Grüneberg.

1840

28. 01. Der alte Feldherr.

24. 09. Shakespeare in der Heimath. Schauspiel in vier Aufzügen.

25. 10. Der dumme Peter. Original-Schauspiel in zwei Akten.

1842

27. 01. Die Wiener in Berlin.

06. 02. Die Wiener in Berlin.

1845

(Posener Stadttheater in Bromberg)

06. 04. Sie schreibt an sich selbst. Lustspiel in einem Akt. Frei nach dem Französischen von Karl von Holtei [Erstaufführung].

25. 04. Hans Jürge, oder Knecht, Diener, Herr. Schauspiel in drei Abteilungen [Erstaufführung].

(Posener Stadttheater in Bromberg)

01. 06. Lenore.

28. $09 . \quad$ Lenore. 
02. 10. Lenore.

13. 12. Dreiunddreißig Minuten in Grüneberg oder der halbe Weg. Posse in einem Akt.

1847

01. 01. Dreiunddreißig Minuten in Grüneberg.

04. 01. Dreiunddreißig Minuten in Grüneberg.

14. 02 . Dreiunddreißig Minuten in Grüneberg.

28. 09. Sie schreibt an sich selbst.

03. 10. Dreiunddreißig Minuten in Grüneberg oder Der halbe Weg.

1848

08. 02. Die weiblichen Drillinge. Liederspiel in einem Akt.

1849

24. 08. Dreiunddreißig Minuten in Grüneberg oder Der Halbe Weg.

20. 09. Lenore.

02. 10. Die weiblichen Drillinge.

\section{1}

10. 01 Lenore.

28. 03. Die Wiener in Berlin. Mit neuen Einlagen.

04. 12. Mozarts Gedächtnis-Feier. Zum Schluß: „Was können wir von Mozart lernen“. Gedicht von Karl von Holtei.

16. 12. Dreiunddreißig Minuten in Grüneberg, oder: Der halbe Weg.

1852

19. 08. Der Kalkbrenner.

1853

01. 03. Ein Achtel vom großen Loose.

1854

03. 02. Viel Lärm um Nichts. Lustspiel in drei Akten von Shakespeare. Für die deutsche Bühne eingerichtet von C. v. Holtei.

14. 02. Die Komödie der Irrungen. Für die deutsche Bühne eingerichtet von C. v. Holtei.

12. 04. Dreiunddreißig Minuten in Grüneberg, oder: Der halbe Weg.

01. 05. Wiener in Paris. Komisches Charakterbild in zwei Akten [Posener Erstaufführung].

15. 05. Wiener in Paris. Komisches Charakterbild in zwei Akten.

17. 05. Lorbeerbaum und Bettelstab, oder: Drei Winter eines deutschen Dichters. Schauspiel in drei Akten mit einem Nachspiel: Bettelstab und Lorbeerbaum, oder: Zwanzig Jahre nach dem Tode.

07. 10. Lenore.

1857

26. 11. Dreiunddreißig Minuten in Grüneberg, oder: Der halbe Weg. 
1858

26. 08. Dreiunddreißig Minuten in Grüneberg, oder: Der halbe Weg.

\section{4}

15. 11. Lorbeerbaum und Bettelstab, oder: Drei Winter eines deutschen Dichters. Schauspiel in drei Akten mit einem Nachspiel: Bettelstab und Lorbeerbaum, oder: Zwanzig Jahre nach dem Tode [Neu einstudiert].

\section{0}

20. 03. Die Wiener in Paris. Lebensbild mit Gesang in zwei Akten.

27. 12. Lorbeerbaum und Bettelstab, oder: Drei Winter eines deutschen Dichters. Schauspiel in drei Akten mit einem Nachspiel: Bettelstab und Lorbeerbaum, oder: Zwanzig Jahre nach dem Tode.

\section{1}

23. 01. Lorbeerbaum und Bettelstab, oder: Drei Winter eines deutschen Dichters. Schauspiel in drei Akten mit einem Nachspiel: Bettelstab und Lorbeerbaum, oder: Zwanzig Jahre nach dem Tode.

05. 02 Lenore.

21. $02 . \quad$ Lenore. 